\title{
ACESSO À JUSTIÇA NO ESTADO DE SANTA CATARINA: Os Desafios da Atuação da Defensoria Pública
}

\begin{abstract}
Júlia Farah Scholz
Acadêmica de Direito pelo Centro Universitário - Católica de Santa Catarina em Joinville/SC e estagiária no 10 . Ofício da Defensoria Pública do Estado de Santa Catarina em Joinville/SC. julia.farah.scholz@gmail.com e julia. scholz@catolicasc.org.br
\end{abstract}

\section{Luciene Dal Ri}

Doutora em Direito Civil-romanístico pela Università degli Studi di Roma - La Sapienza. Mestre em Estudos Medievais pela Pontificia Università Antonianum. Professora no curso de Graduação em Direito no Centro Universitário "Católica de Santa Catarina" e no programa de Pós-Graduação Stricto Sensu, Mestrado e Doutorado, em Ciência Jurídica na Universidade do Vale do Itajaí (Univali). luciene.dalri@univali.br

\section{Resumo}

A Defensoria Pública, com previsão constitucional no artigo134, instituída e regulamentada pela Lei Complementar n. 80/1994, é tida como órgão que exerce função essencial à promoção de justiça. Sua atribuição vai além da assistência e orientação jurídica, pois atua como veículo de transformação social e afirmação do princípio da dignidade da pessoa humana. A atuação da Defensoria Pública na defesa dos interesses daqueles que apresentam alguma vulnerabilidade, seja econômica ou social, ocorre de forma ampla, visando a dar concretude ao Estado Democrático de Direito. Ocorre que a instituição sofre algumas restrições no Estado de Santa Catarina, onde foi instalada recentemente em virtude de duas ações diretas de inconstitucionalidade junto ao STF, que concederam o prazo de 12 meses para 0 Estado regularizar a situação. Nesse sentido, 0 artigo apresenta, por intermédio da pesquisa bibliográfica e do método dedutivo, a relevância da Defensoria Pública para a manutenção dos direitos humanos fundamentais, e em contrapartida, a restrição do acesso à Justiça no Estado de Santa Catarina. Para solucionar o problema da falta de defensores públicos e o consequente impedimento do pleno acesso à Justiça, necessária se faz a ampliação do número de Defensores Públicos, do quadro de apoio e a melhoria da estrutura física.

\section{Palavras-chave}

Assistência jurídica. Função essencial à justiça. Minorias. Vulnerabilidade. 


\section{ACCESS TO JUSTICE IN SANTA CATARINA STATE: THE CHALLENGES OF THE OPERATION OF THE PUBLIC DEFENSE}

\section{Abstract}

The Public Defender's Office is inserted in the article 134 of the Brazilian Constitution, which was established and regulated by the Complementary Law $n$. 80/1994, and it is also seen as an institution that performs an essential role on the promotion of justice. Its assignment goes beyond assistance and legal aid, as it acts as a vehicle for social change and affirmation of the principle of human dignity. The duty of the Public Defense Service in defending the interests of those who have some vulnerability, whether economic or social, is broadly aimed to give concreteness to the Democratic State based on the rule of law. However, the Public Defense faces some restrictions in the state of Santa Catarina, where has recently been installed as a result of two Direct Actions of Unconstitutionality in the Federal Court of Justice (STF), which has given 12 months for the State of Santa Catarina to rectify the situation. Thereby, this article presents, through a bibliographic research and the deductive method, the relevance of the Public Defense Service for the maintenance of fundamental human rights, on the other hand, the restriction of access to justice in the State of Santa Catarina. In order to solve the lack of public defenders and difficulty on access to justice, it is essential to increase the number of public defenders, including civil servants, and improve the structure.

\section{Keywords}

Legal assistance. Essential function to justice. Minorities. Vulnerability.

\section{Sumário}

1 Introdução. 2 Da inconstitucionalidade do acesso à justiça no Estado de Santa Catarina. 3 Da criação da Defensoria Pública no Brasil. 4 Princípios institucionais. 5 Da função essencial à justiça. 6 Da restrição ao acesso à Justiça no estado de Santa Catarina. 7 Conclusão. 8 Referências. 


\section{INTRODUÇÃO}

A Constituição Federal de 1988 introduziu novas garantias aos direitos do cidadão. Entre as inovaçóes, ganha destaque o acesso à Justiça, direito que proporciona a proteção das demais garantias constitucionais. Nesse contexto de mudanças, a criação da Defensoria Pública como meio de acesso dos grupos sociais ou economicamente vulneráveis à justiça, fez jus ao artigo 5º XXXV, o qual determina que "a lei não excluirá da apreciação do judiciário, lesão ou ameaça de direito".

Até então, o Brasil, como Estado Democrático de Direito, não dispunha de meios para efetivar este acesso aos necessitados, tendo em vista o problema da pobreza absoluta e relativa, decorrente das diferenças socioeconômicas presentes no país. Logo, a fim de dar cumprimento ao disposto no artigo 5º, LXXIV, o qual encarrega o Estado de prestar assistência jurídica integral e gratuita aos que comprovem a insuficiência de recursos, a criação da Defensoria Pública fortaleceu os princípios da legalidade, democracia e dignidade da pessoa humana.

Nesse contexto, foi conferido à instituição o patamar de função essencial de justiça, dotada de autonomia funcional e administrativa e concedendo iniciativa da sua proposta orçamentária, conforme dispóe o artigo 134 da Constituição Federal.

No Estado de Santa Catarina a Defensoria Pública foi instituída pela Lei Complementar Estadual no 575, de 2 de agosto de 2012, em consequência ao julgamento procedente de duas açóes diretas de inconstitucionalidade no ano de 2012, as quais promoveram a alteração do artigo104 da Constituição Estadual, inserindo as disposiçôes da Constituição Federal a respeito da Defensoria Pública.

A partir de sua instalação, entretanto, o problema do acesso à Justiça no Estado não foi resolvido, tendo em vista o restrito número de cargos criados e de defensores atuando. Além disso, o fato de a maioria das Comarcas do Estado catarinense não ter Defensoria Pública instalada, prejudica a legitimidade do acesso à Justiça, pois o que ocorre nessas Comarcas é a nomeaçáo de advogados dativos para atuar na defesa dos interessas da parte, o que acaba comprometendo a efetividade de defesa dos seus direitos fundamentais. 


\section{DA INCONSTITUCIONALIDADE DO ACESSO À JUSTIÇA NO ESTADO DE SANTA CATARINA}

A Defensoria Pública do Estado de Santa Catarina foi criada em razão das Açôes Diretas de Inconstitucionalidade de $\mathrm{n}^{\text {os }} 3.892$ e 4.270, as quais foram julgadas procedentes pelo Supremo Tribunal Federal em março de 2012. Na decisão, o Plenário julgou procedente pedido formulado nas duas açóes diretas, ajuizadas pela Associação Nacional dos Defensores Públicos da União - Andpu (atualmente denominada Anadef) - e pela Associaçáo Nacional dos Defensores Públicos - Anadep, para declarar a inconstitucionalidade do artigo 104 da Constituição do Estado de Santa Catarina e da Lei Complementar Estadual no 155/97 que autorizavam e regulavam a prestação de serviços de assistência judiciária por advogados dativos inscritos na Ordem dos Advogados do Brasil - OAB -, em substituição à Defensoria Pública. Observou-se ainda que o modelo catarinense não utilizava a parceria com a OAB como forma de suplementar a Defensoria Pública ou suprir eventuais carências desta, mas, pelo contrário, ao indicar advogados dativos estava cumprindo o papel designado à Defensoria Pública inexistente no Estado catarinense até então.

Conforme a decisão, a inexistência de órgão estatal destinado à orientação jurídica e à defesa dos hipossuficientes no Estado de Santa Catarina, feria a dignidade do ser humano e violava o inciso LXXIV dos artigos $5^{\circ}$ e 134, caput, ambos da Constituição Federal, razão pela qual foi declarada a inconstitucionalidade do artigo 104 da Constituiçáo do Estado de Santa Catarina e da Lei Complementar Estadual no 155/1997, as quais dispunham sobre a prestação de assistência judiciária gratuita, realizada, até entáo, por meio de convênio com a $\mathrm{OAB} / \mathrm{SC}$, mediante nomeação pelo magistrado de advogados dativos.

Com a procedência das açôes diretas de inconstitucionalidade, o Estado de Santa Catarina teria o prazo de 12 meses para regularizar a situação, de forma a realizar concurso de provas e títulos, a fim de instituir a Defensoria Pública do Estado de Santa Catarina de acordo com a Constituição da República Federativa do Brasil de 1988 e em estrita observância à Lei Complementar 80/1994.

Em virtude da decisão proferida pelo Supremo Tribunal Federal, o Estado de Santa Catarina, por meio da Lei Complementar Estadual no 575, de 2 de agosto de 2012, promoveu as alteraçóes legislativas necessárias para a efetivação da Defen- 
soria Pública nos moldes constitucionais, incluindo nova redação dada ao artigo 104 da Constituição Estadual, bem como instaurando sua sede em Florianópolis e estabelecendo mais 23 núcleos espalhados pelo Estado, contando com técnicos, analistas, estagiários e defensores públicos, cuja investidura no cargo depende de aprovação em concurso de provas e títulos.

Nesse contexto, com a instauração da Defensoria Pública em Santa Catarina, o Estado foi proibido, pela 3a Turma do Tribunal Regional Federal da $4^{a}$ Região, ao julgar improcedente a Apelaçáo manejada pela $\mathrm{OAB}$ catarinense, de celebrar convênios com a Ordem dos Advogados do Brasil para a prestação de serviço de Defensoria Pública por meio de advogados dativos. Tal proibição deu-se em decorrência das decisóes procedentes das açóes diretas de inconstitucionalidade.

Apesar da decisão, na prática o que ocorre é que, nas Comarcas onde não existir Defensoria Pública instalada, nos casos de réu revel ou na esfera criminal, o juiz deve nomear de ofício um defensor dativo, objetivando conferir assistência jurídica aos grupos vulneráveis.

Nesse sentido, Rocha (2007, p. 146) ressalta que "poucos estados onde foi criada a Defensoria Pública fornecem atendimento em todas as comarcas, sendo comum, nestes casos, a nomeação de advogados dativos. " Isto é, nas comarcas onde a Defensoria Pública não foi instituída ou por falta de estrutura adequada para promover o atendimento à população, a nomeaçáo de um defensor dativo é admitida em caráter excepcional, a fim de dar cumprimento ao disposto no artigo $5^{\circ}$ incisos XXXV e LXXIV da Constituição.

É o entendimento do Superior Tribunal de Justiça:

Não havendo ou sendo insuficiente a Defensoria Pública local, ao juiz é conferido o poder-dever de nomear um defensor dativo ao pobre ou revel. Essa nomeação ad hoc permite a realização dos atos processuais, assegurando ao acusado o cumprimento dos princípios constitucionais do Contraditório e da Ampla Defesa (REsp 540.965/RS, Rel. Min. Luiz Fuz, j. em 4/11/2003).

Em relação ao assunto, as decisões do Tribunal Catarinense demonstram esta possibilidade, conforme pode ser observado no Agravo de Instrumento de $\mathrm{n}$. 2014.050095-0, julgado pelo relator Robson Luz Vanella: 
A despeito de ter o Supremo Tribunal Federal declarado a inconstitucionalidade da Lei Complementar Estadual n. 155/1997 e do artigo 104 da Constituição Catarinense, que previa o convênio do Estado com a OAB/SC para a prestaçáo de atividades da defensoria dativa, ainda mostra-se possível a nomeação de curador especial enquanto persistir a impossibilidade de prestação do serviço pela Defensoria Pública do Estado, tendo em vista que a estruturação da Instituição ainda encontra-se em fase de implementação, não contando, também, com o número suficiente de defensores ao atendimento das demandas em curso.

Ocorre que a prestação de assistência jurídica pelos advogados dativos não pode, jamais, ser equiparada ou suplementarmente utilizada (ainda que de forma excepcional) à função exercida pela Defensoria Pública, uma vez a assistência jurídica é função mínima desempenhada pela instituição, posto que sua criação foi destinada a concretizar os direitos humanos, não apenas daqueles economicamente hipossuficientes, mas também das minorias marginalizadas ou excluídas pela sociedade e daqueles socialmente necessitados.

A respeito da relevância funcional conferida à Defensoria Pública, Ré (2014) ensina que:

[...] a identidade entre a Constituição Federal e as funções institucionais da Defensoria Pública, não se esgota no combate à desigualdade social e à marginalização. A sobreposição é muito maior. É estrutural. Para concretização do projeto constitucional, a implementaçáo e o fortalecimento da Defensoria Pública ganham tez de fundamentalidade (p. 60).

Com o propósito de firmar a importância da instalação da Defensoria Pública nos Estados, a Lei Complementar 80/94 foi alterada, em 2009, pela Lei Complementar $n^{\circ} 132$, a qual fez constar no artigo $1^{\circ}$ a relevância da Defensoria Pública como instrumento de afirmação do Estado Democrático de Direito e expressão do princípio da dignidade da pessoa humana, sendo, portanto, imprescindível para a efetivação aos direitos humanos.

\section{DA CRIAÇÃO DA DEFENSORIA PÚBLICA NO BRASIL}

A Constituição da República Federativa do Brasil, promulgada em 1988, assegurou, dentre o rol de direitos e deveres individuais e coletivos presentes no artigo $5^{\circ}$ LXXIV, o dever de o Estado prestar assistência jurídica integral e gra- 
tuita aos que comprovarem insuficiência de recursos. Até então, as constituiçóes anteriores mencionavam o direito à assistência judiciária, porém não identificam o órgão incumbido desta tarefa; daí a necessidade de uma instituição que fosse independente e voltada a prestar assistência jurídica aos necessitados. Nesse aspecto, em razão de não haver previsão constitucional de um órgão específico para prestar assistência jurídica aos necessitados antes de 1988, tal função era exercida por advogados remunerados pelo Poder Público, membros do Ministério Público ou órgãos ligados ao Poder Executivo, tais como as Procuradorias de Assistência Judiciária (Novelino, 2014, p. 989).

Galliez (2009, p. 17) lembra o caso do Estado do Rio de Janeiro, onde o início da criação da Defensoria Pública deu-se com a Lei no 5.111 de 8 de dezembro de 1962, denominada Lei Orgânica do Ministério Público e da Assistência Judiciária, a partir da qual originaram-se os primeiros cargos de Defensor Público; no entanto, por se tratarem de cargos isolados, os defensores eram submetidos à chefia do Procurador Geral do Estado. Como consequência, a partir do ano de 1970 uma série de leis complementares tentou dar autonomia administrativa à instituição da Assistência Judiciária, porém, somente com a Lei Complementar no 55 de 1989, a instituição passou a se chamar Defensoria Pública.

Mais tarde foi promulgada a lei Complementar no 80 de 12 de janeiro de 1994, de caráter nacional, visando o cumprimento do disposto no artigo 24, XIII do texto constitucional, o qual dispóe que "Compete à União, aos Estados e ao Distrito Federal legislar concorrentemente sobre assistência jurídica e Defensoria Pública”, que passou a regulamentar a Defensoria Pública da União, do Distrito Federal e dos Territórios, além de dispor normas gerais de organização da Defensoria Pública dos Estados.

A intençáo de efetivar o direito contido no artigo $5^{\circ}$ LXXIV da Carta Magna, segundo destaca Branco (2012, p. 1.089) foi consagrado na Emenda Constitucional no 45 que acresceu o parágrafo segundo ao artigo 134, ao designar a Defensoria Pública como instituição essencial à função jurisdicional do Estado, incumbindo-lhe a orientação jurídica e a defesa, em todos os graus, dos necessitados, e, ainda, conferindo-a autonomia funcional, administrativa e orçamentária. 


\section{PRINCÍPIOS INSTITUCIONAIS}

A Lei Complementar Federal no 80 de 12 de janeiro de 1994, previu, no artigo $3^{\circ}$, como princípios institucionais da Defensoria Pública, a unidade, a indivisibilidade e a independência funcional.

Afirmar que a unidade é um princípio desta instituição, significa que ela opera como um todo, isto é, "A unidade consiste, pois, na realização contínua e permanente de todos os mecanismos inerentes à atuação do Defensor Público" (Galliez, 2009, p. 30).

Ao referir-se à Defensoria Pública como uma unidade, deve-se observar a garantia da inamovibilidade prevista nos artigos 34, 79 e 118 da Lei Complementar no 80/94, que garante ao defensor público que não poderá ser removido em razão de questóes pessoais ou políticas. Caso fosse possível, a infraestrutura, conforme assinala Galliez (2009, p. 30), estaria comprometida, prejudicando também os assistidos.

Pelo princípio da indivisibilidade, a Defensoria Pública tem a responsabilidade de preservar a instituição zelando pelas funçôes atribuídas pelo artigo $1^{\circ}$ da LC 80/94. Por ser indivisível, a assistência jurídica deve ser prestada até que o objetivo seja alcançado, ou seja, até que a resolução do problema trazido pelo assistido ocorra independentemente do membro que irá atuar.

Lima (2012, p. 97) explica que "A indivisibilidade indica que os membros da Defensoria Pública podem ser substituídos uns pelos outros sem que haja prejuízo ao exercício das funçôes do órgão”. Nesse sentido, haverá designação de um defensor Público substituto no caso de férias, impedimento, afastamento ou licenças, garantindo também o princípio da eficiência previsto no artigo 37 da Carta Constitucional.

O princípio da independência funcional possibilita que o defensor adote posicionamento próprio sobre questóes relativas ao assistido, estando, então, independente dos posicionamentos adotados pelos outros defensores públicos.

Algumas prerrogativas concedidas aos defensores públicos derivam do princípio da indivisibilidade, como, por exemplo, a contagem de todos os prazos em dobro e a intimaçáo pessoal (artigo 128, I da LC no 80/94), e a proibição do 
exercício da advocacia fora das atribuiçóes institucionais (artigo 134 da CRFB/88; artigo 130 da LC no 80/94 e artigo $104 \$ 3^{\circ}$ da Constituiçáo do Estado de Santa Catarina).

Com a Emenda Constitucional 45 de 2004, foi conferido às Defensorias Públicas estaduais a autonomia funcional e administrativa, a fim de cumprir sua função essencial à Justiça, garantia esta confirmada pelo artigo $104 \$ 1^{\circ}$ da Constituição do Estado de Santa Catarina. Isso significa que a instituição está desvinculada dos demais órgãos públicos, ou, em outras palavras, como ensina Galliez (2009, p. 44), "A independência funcional assegura a plena liberdade de ação do defensor público perante todos os órgãos da administração pública, especialmente o judiciário. ”

\section{DA FUNÇÃO ESSENCIAL À JUSTIÇA}

A Constituição Federal, ao assegurar em seu artigo $5^{\circ}$, inciso LXXIV, que “o Estado prestará assistência jurídica integral e gratuita aos que comprovarem insuficiência de recursos", deliberou o exercício de tal função à Defensoria Pública, considerando a atuação da instituição como função essencial à Justiça.

Nesse sentido, Galliez (2009, p. 15) ressalta que

A importância dada à prestaçấo da assistência jurídica aos necessitados foi de tal ordem que a Defensoria Pública constou pela primeira vez do texto constitucional federal, sendo considerada inclusive como função essencial à justiça (Título IV, Capítulo IV, Seçáo III, arts. 134 e 135).

A Lei Complementar no 80/94 organiza a Defensoria Pública da União, do Distrito Federal e dos Territórios, prescrevendo normas gerais de organização. Dentre as funçôes estabelecidas pela Constituição Federal, o artigo $1^{\circ}$ da lei traz a seguinte redação:

Art. 1º Aefensoria Pública é instituição permanente, essencial à função jurisdicional do Estado, incumbindo-lhe, como expressão e instrumento do regime democrático, fundamentalmente, a orientação jurídica, a promoção dos direitos 
humanos e a defesa, em todos os graus, judicial e extrajudicial, dos direitos individuais e coletivos, de forma integral e gratuita, aos necessitados, assim considerados na forma do inciso LXXIV do artigo $5^{\circ}$ da Constituição Federal.

A hipossuficiência de recursos deve ser interpretada de forma ampla, uma vez que, tendo funçóes típicas e atípicas, a Defensoria Pública protege tanto aqueles hipossuficientes econômicos quanto aqueles que comprovem vulnerabilidade distinta da financeira. Assim, os termos insuficiência de recursos (artigo 5o LXXIV, CRFB/88) e necessitados (artigo 134, CRFB/88), conforme salienta Lima (2012, p. 166), não devem ser entendidos como sinônimos, uma vez que a vulnerabilidade exigida no texto legal pode ser caracterizada na carência financeira ou na vulnerabilidade de ordem jurídica, organizacional ou, ainda, social. Nesse sentindo, são considerados socialmente necessitados, por exemplo, os consumidores, os usuários de serviços públicos, os usuários de plano de saúde, os que queiram instituir ou contestar políticas públicas, como as atinentes à saúde, à moradia, ao saneamento básico, ao meio ambiente, etc. (Ré, 2014, p. 42).

A fim de concretizar sua função essencial à Justiça, a lei atribuiu como função mínima ao órgão a defesa dos necessitados, tendo como principais razões de existência a carência financeira e a proteção aos economicamente fracos. Em outras palavras,

Por intermédio da Defensoria Pública, garante-se que o cidadão economicamente vulnerável possa ser auxiliado juridicamente, quer na esfera extrajudicial, como é o caso da consultoria jurídica, da conciliaçáo prévia, do assessoramento e da defesa em processos administrativos, quer na esfera judicial, cujo exemplo mais evidente é o ajuizamento de demandas para postulação de direitos (Lima, 2012, p. 172).

A instituição foi incumbida, portanto, de prestar assistência e orientação jurídica àqueles tidos como hipossuficientes, de forma gratuita e em todos os graus de jurisdição, atuando também em questóes judiciais ou extrajudiciais. Nesse aspecto, conforme Rocha (2007, p. 144-145) ensina, o texto legal, ao estabelecer como função das Defensorias Públicas a orientação extrajudicial, possibilita a prevenção de litígios e contribui para que os grupos vulneráveis tenham conhecimento de seus direitos e garantias fundamentais. 
O trabalho desenvolvido pela instituição vai além das funçôes elencadas pelo dispositivo constitucional, uma vez que a possibilidade de ajuizamento de ação civil pública faz da Defensoria Pública um instrumento de transformação social, dando legitimidade às minorias a fim de que busquem do Estado o acesso à Justiça, titulando-as como legitimadas para o exercício do poder constituinte. Destacando essa importância, Galliez (2009, p. 80) explica que "O assistido da Defensoria Pública representa uma singularidade que integra a multidão, sendo sua luta biopolítica e de resistência, destinada a romper a estrutura do poder que os explora e os marginaliza”. Isto é, além de sua função essencial à Justiça, a instituição opera como instrumento de transformação social, atuando também em conflitos coletivos, como é o caso do direito de moradia da população carente e daqueles marginalizados pelo sistema carcerário, de forma a legitimar as minorias para o exercício do poder constituinte, criando políticas para reinseri-los na sociedade e torná-los cidadáos efetivamente, não apenas formalmente. Por consequência, Galliez (2009, p. 76) enfatiza a urgência da transformação da estrutura do Estado, com a participação ativa das minorias, não cabendo à Defensoria Pública apenas a promoção de assistência jurídica como instrumento de acesso à Justiça, uma vez que suas funçôes ultrapassam a igualdade formal preconizada pelos cânones tradicionais do constitucionalismo.

Nesse contexto, uma das ações da instituição busca dar efetividade à garantia constitucional de acesso à Justiça, prevista no artigo $5^{\circ} \mathrm{LXXIV}$; os procedimentos extrajudiciais de resolução de conflitos conferem meios alternativos à solução judicial. A respeito do assunto, Rosenblatt (2014) esclarece que:

Esta vinculação temática decorre năo apenas do fato de que a Instituição foi criada constitucionalmente para a concretização da garantia do acesso à justiça, mas também porque nasce vocacionada para este mister, como demonstra o imperativo legal de suas atribuiçóes, previstas no artigo $4^{\circ}$, inciso II da Lei Complementar 80/94 (p. 23).

O papel da Defensoria Pública não se limita apenas à promoção de Justiça; vai além da atuação em prol da efetiva participação dos economicamente pobres garantindo-lhes o acesso à Justiça, dado que o condão principal da instituição é o fortalecimento da democracia e da cidadania, e a preservação da dignidade da pessoa humana, tornando legítimo o Estado Democrático de Direito. 


\section{DA RESTRIÇÃO DO ACESSO À JUSTIÇA NO ESTADO DE SANTA CATARINA}

O Estado de Santa Catarina é formado por 111 comarcas, no entanto a Defensoria Pública (até outubro de 2015) foi instaurada em apenas 24 destas, quais sejam: Florianópolis, Araranguá, Blumenau, Brusque, Caçador, Campos Novos, Chapecó, Concórdia, Criciúma, Curitibanos, Itajaí, Jaraguá do Sul, Joinville, Joaçaba, Lages, Mafra, Maravilha, Palhoça, Rio do Sul, São José, São Miguel do Oeste, São Lourenço do Oeste, Tubarão, e Xanxerê. Percebe-se que as áreas de atuação da Defensoria Pública ainda são restritas, pois há apenas 103 defensores públicos atuando no Estado. Anteriormente, a Ordem dos Advogados do Brasil de Santa Catarina - OAB/SC - contava com cerca de 9 mil advogados inscritos no sistema de Defensoria Dativa.

Os 103 defensores públicos em atividade no Estado, segundo informaçóes no endereço virtual da instituição, têm atribuições para atuar nas áreas da família, cabendo à Defensoria Pública operar na defesa das famílias atendendo pessoas ou grupo de pessoas que necessitem da instituição para resolver problemas como, por exemplo, alimentos, separaçóes, investigação de paternidade, guarda e tutela, interdição, dissolução de união estável, adoção de pessoas com mais de 18 anos, regulamentação de visitas, etc.; cível, compreendendo a defesa de interesses em açóes possessórias de despejo, para tutela da moradia, para fornecimento de medicamentos, internação hospitalar de tratamento de toxicômano e para garantir o direito à educação; extrajudicial, os conflitos serão prioritariamente solucionados por meio de mecanismos extrajudiciais (conciliação e mediação), formatando acordos, sem necessidade de audiência, que geram títulos passíveis de execução judicial no caso de descumprimento; penal e execução penal corresponde essencialmente à defesa dos direitos dos acusados em inquéritos policiais e processos desta natureza que tramitem na Justiça Estadual e dos encarcerados, provisórios ou definitivos em todas as instâncias, de maneira integral e gratuita; defesa à mulher, que inclui a assistência, serviços, programas e açóes voltadas ao combate à violência doméstica e familiar contra a mulher; e tutela coletiva, em razão de a Defensoria Pública possuir a prerrogativa legal de propor açóes civis públicas na defesa coletiva de cidadãos carentes. 
Considerando a abrangência de suas atribuiçóes, o número de defensores públicos em atuação é considerado baixo, quando comparado ao volume da demanda, tanto em relação à assistência e à orientação jurídica quanto em relação aos atendimentos direcionados a promover uma soluçáo extrajudicial do conflito. Segundo estudos do Instituto de Pesquisa Econômica Aplicada - Ipea, o Estado de Santa Catarina necessita de 509 Defensores Públicos.

Para tanto, visando a analisar a situação do Estado de Santa Catarina e de todo o país, o relatório do Mapa da Defensoria Pública realizado, pela Associação Nacional dos Defensores Públicos (Anadep), analisou relaçáo por cargos existentes, constatando que o Estado apresenta uma taxa de 74.849 pessoas com até três salários-mínimos por cargo de defensor público existente, representando o único Estado que figura na faixa superior a 40.000, o que denota que o número de cargos existentes é claramente inferior ao necessário.

De acordo com o relatório, em âmbito nacional o número de pessoas com rendimento mensal de até três salários-mínimos por cargo existente de defensor público no Brasil é 18.336. Essa proporção, no entanto, sobe para 56.620 quando a comparação é feita com cargos providos.

Com base nessas informações, foi possível constatar qual o déficit de defensores públicos no Brasil, avaliando qual seria o número sugerido para determinado número de pessoas, fazendo com que todas as comarcas possam ser atendidas. Nesse sentido, a pesquisa adotou como parâmetro a recomendação do Ministério da Justiça, segundo a qual "a relação recomendável de Defensores Públicos por habitante deve oscilar na faixa aproximada de um defensor público para cada dez mil ou, no máximo, 15 mil que possam ser considerados alvo da Defensoria Pública” (Ofício no 287-2011/SRJ-MJ, de 17 de março de 2011).

A partir das informaçóes fornecidas pela Associação Nacional dos Defensores Públicos (Anadep), e considerando que o Estado de Santa Catarina é o $11^{\circ}$ Estado mais populoso do país, possuindo cerca de 6.248.436 habitantes (conforme dados do IBGE referente ao ano de 2014), e apesar de ter o segundo melhor Índice de Desenvolvimento Humano do país (0.840), a Região Sul, composta pelos Estados de Santa Catarina, Paraná e Rio Grande do Sul, representa cerca de 8\% do nível de pobreza do país. Deste valor, $11,4 \%$ reside no estado catarinense. Deste valor, 
em consonância com os dados obtidos pelo Censo 2010 realizado pelo IBGE, aproximadamente $28 \%$ dos homens e $27 \%$ das mulheres catarinenses recebem de 2 a 3 salários mínimos mensais, e o rendimento nominal mensal domiciliar per capita da população residente, em 2014, era, em média, R\$1.245,00.

Essas informaçōes demonstram que, apesar do alto desenvolvimento do país, há uma considerável parcela da população que anseia pela efetivação dos direitos fundamentais, para que sejam vistos como cidadãos perante o Estado e a sociedade, para que a igualdade preconizada pela Constituiçâoo Federal deixe de ser um alvo de difícil alcance. Nesse sentido, Rosenblatt (2014) considera que

Forçoso é reconhecer que de nada adianta a Constituição proclamar em seu art. $1^{\circ}$, que a "República Federativa do Brasil, formada pela união indissolúvel dos Estados e Municípios e do Distrito Federal, constitui-se em Estado Democrático de Direito", quando esse próprio Estado náo permite à parcela significativa da nação o acesso aos seus direitos, nem às técnicas e aos mecanismos de proteção disponíveis para a sua defesa (p. 26).

É nesse contexto que nasce a necessidade de uma instituição forte e autônoma dirigida aos interesses das minorias. Para tanto, foi criada a Defensoria Pública do Estado de Santa Catarina, a qual, conforme dados fornecidos pelo Mapa da Defensoria Pública no Brasil, realizado pela Anadep concentram sua maior atuação nas áreas criminal, cível, família e execução penal.

A necessidade de ampliar o número de defensores públicos no Estado destinados à defesa dos direitos das minorias e à redução das desigualdades sociais, sob primazia da dignidade da pessoa humana, deriva, também, do princípio do devido processo legal, uma vez que

A norma constitucional garante, já na seara judicial, o contraditório, a ampla defesa, o juiz natural, o devido processo legal: porém o cidadáo desprovido de recursos, por não contar com uma defesa técnica de qualidade, já que a advocacia privada implica custos elevados, não conseguirá fazer valer tais garantias, o que significa, de certo modo, verdadeira dupla insuficiência de proteção (Rosenblatt, 2014, p. 27). 
A fim de dar efetividade à instituição, primordial se faz, portanto, a ampliação do quadro de defensores públicos, no intuito de se chegar ao número de 509 defensores públicos, indicado pelo Instituto de Pesquisa Econômica aplicada (Ipea), o que possibilitaria a instalação da Defensoria Pública em todas as Comarcas do Estado, atendendo de forma plena toda a população vulnerável. Consequentemente, também se fazem necessários o aumento dos quadros de apoio (analistas técnicos, técnicos administrativos e estagiários) e a melhoria da estrutura física dos Núcleos da Defensoria Pública.

Desta forma, a Defensoria Pública poderá exercer plenamente seu papel constitucional protegendo os direitos fundamentais sob a égide do princípio da dignidade da pessoa humana, trazendo cidadania aos vulneráveis. Por conseguinte, adotando as palavras de Ré (2014, p. 202), "Que a Defensoria Pública seja a luz e o amor no Brasil”, de modo que onde houver violação dos direitos fundamentas e da dignidade da pessoa carente, a Defensoria Pública estará legitimada a cessar tal situação degradadora dos valores constitucionais.

\section{CONCLUSÃO}

Antes da promulgação da Constituição de 1988 não havia um órgão especializado incumbido de presar assistência jurídica aos necessitados, e tal função era exercida por advogados remunerados pelo Poder Público, por membros do Ministério Público ou, ainda, por órgãos ligados ao Executivo, por exemplo as Procuradorias de Assistência Judiciária.

Com a promulgação da EC 45/2004, a Defensoria Pública ganhou maior importância, tal qual pode ser identificada nos princípios institucionais estabelecidos, principalmente em relaçáo à autonomia funcional e administrativa e pela iniciativa de proposta orçamentária, conforme preceitua o artigo 134, $₫ 2$ da Constituição.

O principal objetivo da Defensoria Pública é, portanto, proporcionar representatividade àqueles grupos considerados vulneráveis, de modo a oferecer medidas judiciais e extrajudiciais mediante assistência, orientação e conciliação, aptas a sanar qualquer ofensa aos seus direitos fundamentais, em especial à dignidade da pessoa humana. 
A atuação da Defensoria Pública é imprescindível para a prestação da garantia fundamental à assistência jurídica às minorias e grupos socialmente excluídos ou marginalizados, de forma a defender seus direitos perante o Estado e os entes privados, e, consequentemente, contribuir para a redução das desigualdades sociais.

Desta forma, cabe ao Estado de Santa Catarina a tarefa de ampliar satisfatoriamente a atuação da Defensoria Pública por meio da instalação de Núcleos em todas as Comarcas do Estado, efetivando, assim, o direito ao devido processo legal e à dignidade da pessoa humana, princípio fundamental no Estado Democrático de Direito.

\section{REFERÊNCIAS}

ASSOCIAÇÃO NACIONAL DOS DEFENSORES PÚBLICOS. Anadep. Mapa da defensoria pública no Brasil. Disponível em: <https://www.anadep.org.br/wtksite/mapa_da_defensoria_publica_no_brasil_impresso_.pdf $>$. Acesso em: 11 nov. 2015.

BRASIL. Constituição (1988). Constituição da República Federativa do Brasil. Brasília, DF: Senado Federal, 1988.

. Lei Complementar n. 80 de 12 de janeiro de 1994.

. Tribunal de Justiça do Estado de Santa Catarina. Agravo de Instrumento $n$. 2014.050095-0, de Joinville, Relator: Desembargador Robson Luz Varella. 2014. Disponível em: <http://app6.tjsc.jus.br/cposg/servlet/ServletArquivo?cdProcesso=01000SC710000\&n uSeqProcessoMv=null\&tipoDocumento=D\&cdAcordaoDoc=null\&nuDocumento=85270 62\&pdf=true>. Acesso em: 13 nov. 2015.

. Supremo Tribunal Federal. Ação direta de inconstitucionalidade - ADI nº3892/SC, rel. Min. Joaquim Barbosa, 14.3.2012. 2012a. Disponível em: <http://www.stf.jus.br/portal/ processo/verProcessoAndamento.asp?numero $=3892 \&$ classe $=A D I \&$ origem $=A P \&$ recurso $=0$ \&tipoJulgamento $=\mathrm{M}>$. Acesso em: 15 nov. 2015.

Supremo Tribunal Federal. Ação direta de inconstitucionalidade - ADI no 4270/ SC, rel. Min. Joaquim Barbosa, 14.3.2012. 2012b. Disponível em: <http://www.stf.jus.br/ portal/processo/verProcessoAndamento.asp?numero $=4270 \&$ classe $=$ ADI\&origem $=A P \&$ rec urso=0\&tipoJulgamento=M.>. Acesso em: 15 nov. 2015. 
DEFENSORIA PÚBLICA DO ESTADO DE SANTA CATARINA. DPE. História. Disponível em: <http://www.defensoria.sc.gov.br/index.php/site-map/histórico>. Acesso em: 20 out. 2015.

. Defensores públicos. Disponível em: <http://www.defensoria.sc.gov.br/index.php/ site-map/defensores>. Acesso em: 20 out. 2015.

GALlIEZ, Paulo. Principios Institucionais da Defensoria Pública. 3. ed. Rio de Janeiro: Lumen Juris, 2009.

INSTITUTO BRASILEIRO DE GEOGRAFIA E ESTATÍSTICA. IBGE. Censo demográfico 2010. Estado de Santa Catarina. Disponível em: <http://www.ibge.gov.br/estadosat/temas. php?sigla=sc\&tema=censodemog2010_rend $>$. Acesso em: 21 out. 2015.

LELLIS, Leonardo. OAB-SC recomenda que advogados dativos não atuem. Revista Consultor Juridico. Disponível em: <http://www.conjur.com.br/2013-jul-15/oab-sc-recomenda-advogados-dativos-nao-atuem-pagamento-divida>. Acesso em: 15 nov. 2011.

LIMA, Frederico Rodrigues Viana de Lima. Defensoria Pública. 2. ed. Salvador, BA: Jus Podivm, 2012.

MENDES, Gilmar Ferreira; BRANCO, Paulo Gustavo Gonet. Curso de direito constitucional. 7. ed. São Paulo: Saraiva, 2012.

NOVELINO, Marcelo. Manual de direito constitucional. 9. ed. Rio de Janeiro: Método, 2014.

RÉ, Aluísio Iunes Monti Ruggeri. Manual do defensor público: teoria e prática. 2. ed. Salvador, BA: JusPodivm, 2014.

ROCHA, Paulo Osório Gomes. Concretização de direitos fundamentais na perspectiva juridico-constitucional da Defensoria Pública: um caminho ainda a ser trilhado. 2007. Disponível em: <http://www.direitopublico.idp.edu.br/index.php/direitopublico/article/view/406/954>. Acesso em: 10 nov. 2015.

ROSENBLATT, Ana et al. Manual de Mediação para defensoria pública. 1. ed. Brasília, DF: Fundação Universidade de Brasília; FUB, 2014.

SUPREMOTRIBUNAL FEDERAL. STF. Informativo n 658. Disponível em: <http://www. stf.jus.br/arquivo/informativo/documento/informativo658.htm>. Acesso em: 15 nov. 2015.

Recebido em: 24/11/2015

Aceito em: 26/1/2016 